\title{
Genetic Analysis of a Large Family with Migraine, Vertigo, and Motion Sickness
}

\author{
Leema Reddy Peddareddygari ${ }^{\circ}$, Phillip D. Kramer, Philip A. Hanna, \\ Mark A. Levenstien, Raji P. Grewal
}

\begin{abstract}
Background: Migraine is a common disorder most typically presenting as headache and often associated with vertigo and motion sickness. It is a genetically complex condition with multiple genes ultimately contributing to the predisposition and development of this episodic neurological disorder. We identified a large American family of 29 individuals of which 17 members suffered from at least one of these disorders, migraine, vertigo, or motion sickness. Many of these individuals suffered from several simultaneously. We hypothesized that vertigo and motion sickness may involve genes that are independent to those directly contributing to migraine susceptibility. Methods: Genome-wide linkage analysis performed using 400 microsatellite repeat markers spaced at $10 \mathrm{cM}$ throughout the genome. The members of this family were phenotyped for each condition, migraine, vertigo, and motion sickness and analyzed separately. Statistical analysis was performed using two-point and multipoint linkage analysis employing a number of models including autosomal recessive or dominant patterns of inheritance with high and low genetic penetrance. Results: We identified a novel locus for migraine, 9q13-q22 (maximum two-point logarithm of odds [LOD] score-2.51). In addition, there are suggestive LOD scores that localize to different chromosomes for each phenotype; vertigo (chromosome 18, LOD score of 1.82) and motion sickness (chromosome 4, LOD score of 2.09). Conclusions: Our analysis supports our hypothesis that the migraine-associated vertigo and motion sickness may involve distinct susceptibility genes.
\end{abstract}

RÉSUMÉ: Analyse génétique d'une famille étendue dont les membres souffrent de migraines, de vertiges et du mal des transports. Contexte : La migraine est un trouble courant qui entraîne habituellement des maux de tête et qui est souvent associé à des vertiges et au mal des transports. Il s'agit aussi d'une condition génétique complexe en vertu de laquelle de nombreux gènes contribuent à terme à cette prédisposition et au développement de ce trouble neurologique périodique. À cet égard, nous avons identifié une famille étendue américaine comptant 29 membres. De ce nombre, 17 d'entre eux avaient souffert d'au moins un de ces troubles : des migraines, des vertiges ou le mal des transports. À noter que plusieurs d'entre eux avaient souffert de ces troubles en même temps. Nous avons émis l'hypothèse que les vertiges et le mal des transports pourraient impliquer des gènes qui sont indépendants de ceux contribuant directement à la propension aux migraines. Méthodes : Nous avons effectué une analyse de liaison au moyen de 400 marqueurs microsatellites répétés et espacés à tous les $10 \mathrm{~cm}$ au sein de l'ensemble du génome des membres de cette famille. Les membres de cette famille ont été « phénotypés » pour chaque type de trouble (les migraines, les vertiges et le mal des transports) et ont été ensuite analysés de façon séparée. Nous avons effectué une analyse statistique au moyen de l'analyse de liaison multipoint et à deux points, utilisant pour ce faire un certain nombre de modèles, par exemple le modèle autosomique récessif ou des patterns dominants de transmission avec une pénétrance génétique élevée ou faible. Résultats : Nous avons été en mesure d'identifier un nouveau locus dans le cas de la migraine : 9q13-q22 (maximum 2-points; score au logarithme des probabilités ou LOD : - 2,51). De plus, il est des scores révélateurs au logarithme des probabilités qui permettent de localiser divers chromosomes pour chaque phénotype : vertiges (chromosome 18 ; score au logarithme des probabilités ou LOD : 1,82) et mal des transports (chromosome 4 ; score au logarithme des probabilités ou LOD : 2,09). Conclusions : Notre analyse confirme ainsi notre hypothèse initiale, à savoir que les cas de migraine auxquels sont associés des vertiges et le mal des transports pourraient très bien impliquer différents gènes de susceptibilité.

Keywords: Migraine, Vertigo, Motion sickness, Linkage analysis, Multiple genetic loci doi:10.1017/cjn.2019.64

Can J Neurol Sci. 2019; 46: 512-517

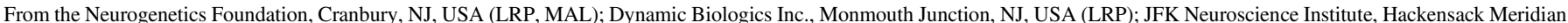

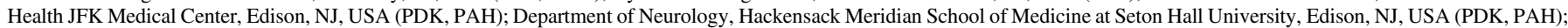
Seton Hall University/Saint Francis Medical Center, Neuroscience Institute, Trenton, NJ, USA (RPG)

Received September 20, 2018. Final Revisions Submitted April 29, 2019. Date of Acceptance April 30, 2019.

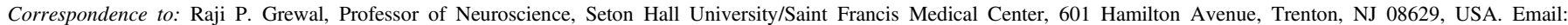
RGrewal@stfrancismedical.org 


\section{INTRODUCTION}

Migraine is a common, debilitating neurological disorder afflicting $12 \%$ of the general population and affecting more women compared to men in a $3: 1$ ratio. ${ }^{1}$ However, its social and economic impact on society goes beyond the suffering of any one individual. In the Global Burden of Disease reported in 2017, it was ranked as one of the most burdensome neurological disorders. ${ }^{2}$

It has been recognized that there is a strong genetic component contributing to the pathophysiology of migraine with first-degree relatives having a fourfold increase in risk for developing this disorder. $^{3,4}$ Furthermore, twin studies suggest a heritability of approximately $42 \% .^{5-7}$ Recent studies have focused on largescale genome-wide association studies. ${ }^{8}$ In spite of advances in technology which allow these large-scale high throughput genetic studies to be completed, the precise genetic basis of migraine remains elusive. In addition to these large-scale studies, there remains scientific value in the study of well-characterized families with complex disorders such as migraine.

We identified an American family in which multiple members were affected with migraine headache, vertigo, and severe motion sickness. We hypothesized that vertigo and motion sickness, which are common comorbidities associated with migraine, may be inherited through different susceptibility genes independent of those conferring a vulnerability to migraine. To test this hypothesis, we performed genetic analysis of each of these disorders separately.

\section{Methods}

\section{Clinical}

We ascertained a multigenerational American family with multiple members affected with migraine associated with motion sickness and vertigo (Figure 1). The family was recruited with policies and procedures approved by the Institutional Review Board (IRB) of the New Jersey Neuroscience Institute, Edison, New Jersey, USA.

All 29 participating family members were interviewed by neurologists (PDK, PAH, and RPG). The diagnosis of migraine was made on the basis of clinical history and met the International Headache Society diagnostic criteria. ${ }^{8}$ Motion sickness was diagnosed by clinical history and examination. Vertigo was diagnosed by clinical history, and a Dix-Hallpike maneuver was performed to exclude benign paroxysmal positional vertigo. A complete vestibular examination was performed including videooculography and a general neurological examination to exclude other vestibular disorders. The family members were coded as affected, probably affected and unaffected for each phenotype.

\section{Genetics}

A blood sample was collected from all members of the family and genomic DNA extracted (Puregene Systems, Gentra). All the DNA samples (both affected and unaffected) were subjected to genetic analysis using 400 microsatellite repeat markers spaced at $10 \mathrm{cM}$ throughout the genome (Weber lab screening set 13, Prevention Genetics Inc., Marshfield, WI, USA).

Statistical analysis was performed using two-point and multipoint linkage analysis and for both of these analyses four disease models were studied (Table 1). Each of the four models, which include a dominant model with incomplete penetrance (high), a recessive model with incomplete penetrance (high), a
Table 1: Penetrance values for each genotype in which + represents the wild type allele and $D$ represents the disease allele. Each penetrance is the probability of an individual being affected conditional on a given genotype at the disease locus

\begin{tabular}{|c|c|c|c|c|}
\hline \multicolumn{2}{|c|}{ Disease model } & \multicolumn{3}{|c|}{ Genotype } \\
\hline & & ++ & D+ & DD \\
\hline \multirow[t]{2}{*}{ Dominant } & High & 0.01 & 0.8 & 0.8 \\
\hline & Low & 0.01 & 0.5 & 0.5 \\
\hline \multirow[t]{2}{*}{ Recessive } & High & 0.01 & 0.01 & 0.8 \\
\hline & Low & 0.01 & 0.01 & 0.5 \\
\hline
\end{tabular}

second dominant model with incomplete penetrance (low), and a second recessive model with incomplete penetrance (low), was employed assuming a disease allele frequency of 0.001 . Mendelian inconsistencies were detected using PEDCHECK. ${ }^{9}$ The two-point parametric linkage analysis was performed using MLINK, ${ }^{10}$ from the LINKAGE programs, and the multipoint parametric linkage analysis was performed using SIMWALK2. ${ }^{11}$ Each logarithm of odds (LOD) score was converted to report a $p$-value by first converting to a chi-squared statistic and then employing the standard statistical tables while taking into account the one-sided nature of the test. The three phenotypic traits, migraine, vertigo, and motion sickness were analyzed individually for all autosomal chromosomes. Employing four genetic models to analyze three phenotypes resulted in 12 genome-wide tests. The $p$-values were adjusted for this multiplicity of testing. ${ }^{12}$

\section{Results}

The clinical features of the individuals participating in the study are indicated in Table 2. It is interesting to note that of 12 individuals in this family that suffer from migraine, only 1 individual (III-5) did not have associated motion sickness or vertigo. This individual married into this family and all of the remaining individuals have a combination of vertigo and/or motion sickness associated with migraine. Furthermore, 16 members of this family suffered from at least one of these three disorders.

It can be noted that we applied the same uniform diagnostic criteria to III-5, as we did with all other members of the pedigree and coded this individual as affected for migraine. From a statistical perspective, there are two possibilities regarding this individual, either the migraine phenotype is due to a mutation in the same gene as those within the pedigree or a different gene representing locus heterogeneity. A priori, it is not possible to know which of these two possibilities are valid. When the etiology of the migraine phenotype is the same gene as the rest of the pedigree, the recombination fraction for that sib pair (including individual III-5) will be the same as for the other sibling pairs in the pedigree and will result in a moderate increase in the LOD score. We tested this pedigree with this assumption recognizing that analysis with locus heterogeneity would result in a moderate decrease in this calculated LOD score. 
Table 2: The clinical features of the individuals participating in the study

\begin{tabular}{|c|c|c|c|c|}
\hline Individual ID & Age at onset & Migraine & Vertigo & Motion sickness \\
\hline II-1 & & - & - & - \\
\hline II-2 & 15 & + & + & + \\
\hline III-1 & 7 & + & + & + \\
\hline III-2 & 12 & - & + & + \\
\hline III-4 & & - & - & - \\
\hline III-5 & 18 & + & - & - \\
\hline III-6 & 20 & - & + & + \\
\hline III-8 & 20 & - & + & $+1-$ \\
\hline III-9 & & - & - & - \\
\hline III-10 & & - & - & - \\
\hline III-12 & Childhood & - & + & $+1-$ \\
\hline III-13 & 10 & + & + & + \\
\hline III-15 & 8 & + & - & + \\
\hline III-16 & & - & - & - \\
\hline III-17 & 8 & + & - & + \\
\hline IV-1 & 5 & - & - & + \\
\hline IV-2 & & - & - & - \\
\hline IV-3 & 10 & $+1-$ & + & + \\
\hline IV-4 & 14 & + & + & + \\
\hline IV-5 & 10 & $+1-$ & - & + \\
\hline IV-6 & & - & - & - \\
\hline IV-7 & & - & - & - \\
\hline IV-8 & & - & - & - \\
\hline IV-9 & & - & - & - \\
\hline IV-10 & 18 & $+1-$ & - & + \\
\hline IV-11 & & - & - & - \\
\hline IV-12 & 8 & $?$ & $?$ & + \\
\hline IV-13 & 5 & + & + & + \\
\hline IV-14 & & - & - & - \\
\hline
\end{tabular}

Table 3: Maximum two point-LOD scores along with their markers and chromosome locations for each genetic model employed and each phenotype analyzed

\begin{tabular}{|c|c|c|c|c|}
\hline \multirow[t]{2}{*}{ Phenotype } & \multicolumn{4}{|c|}{ Model } \\
\hline & Dominant (high) & Dominant (low) & Recessive (high) & Recessive (low) \\
\hline \multirow[t]{2}{*}{ Vertigo } & 1.33 & 1.51 & 1.82 & 1.27 \\
\hline & ATA33B03Z, chr 11 & ATA33B03Z, chr 11 & ATA82B02N,chr 18 & ATA82B02N, chr 18 \\
\hline \multirow[t]{2}{*}{ Migraine } & $2.51^{\mathrm{a}}$ & $2.44^{\mathrm{a}}$ & 1.58 & 0.86 \\
\hline & GATA21F05, chr 9 & GATA21F05, chr 9 & ATA2A03, chr 4 & ATA2A03, chr 4 \\
\hline \multirow[t]{2}{*}{ Motion sickness } & 1.38 & 1.28 & $2.09^{\mathrm{a}}$ & 1.63 \\
\hline & GATA124F08, chr 1 & GGAA20G04, chr 2 & 165zf8ZP, chr 4 & 165zf8ZP, chr 4 \\
\hline
\end{tabular}

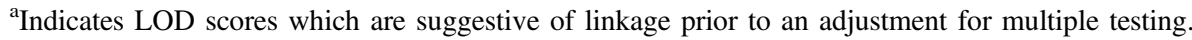


Table 4: Maximum multipoint LOD scores along with their relative map positions and chromosome locations for each genetic model employed and each phenotype analyzed. Relative map positions are calculated relative to the first marker in the Weber lab screening set 13 for each autosomal chromosome

\begin{tabular}{|c|c|c|c|c|}
\hline \multirow[t]{2}{*}{ Phenotype } & \multicolumn{4}{|c|}{ Model } \\
\hline & Dominant (high) & Dominant (low) & Recessive (high) & Recessive (low) \\
\hline \multirow[t]{2}{*}{ Vertigo } & 1.59 & 1.87 & $2.17^{\mathrm{a}}$ & 1.67 \\
\hline & $158.6 \mathrm{cM}, \mathrm{chr} 5$ & $157.8 \mathrm{cM}, \mathrm{chr} 5$ & $114.9 \mathrm{cM}, \mathrm{chr} 18$ & $114.9 \mathrm{cM}, \mathrm{chr} 18$ \\
\hline \multirow[t]{2}{*}{ Migraine } & $2.28^{\mathrm{a}}$ & $2.37^{\mathrm{a}}$ & 1.58 & 0.86 \\
\hline & $88.0 \mathrm{cM}, \mathrm{chr} 9$ & $88.0 \mathrm{cM}, \mathrm{chr} 9$ & $102.8 \mathrm{cM}, \mathrm{chr} 4$ & $102.8 \mathrm{cM}, \mathrm{chr} 4$ \\
\hline \multirow[t]{2}{*}{ Motion sickness } & $1.92^{\mathrm{a}}$ & 1.61 & $2.17^{\mathrm{a}}$ & 1.77 \\
\hline & $250.6 \mathrm{cM}, \mathrm{chr} 1$ & $250.6 \mathrm{cM}, \mathrm{chr} 1$ & $220.7 \mathrm{cM}, \mathrm{chr} 4$ & $223.6 \mathrm{cM}, \mathrm{chr} 4$ \\
\hline
\end{tabular}

${ }^{\mathrm{a}}$ Indicates LOD scores which are suggestive of linkage prior to an adjustment for multiple testing.
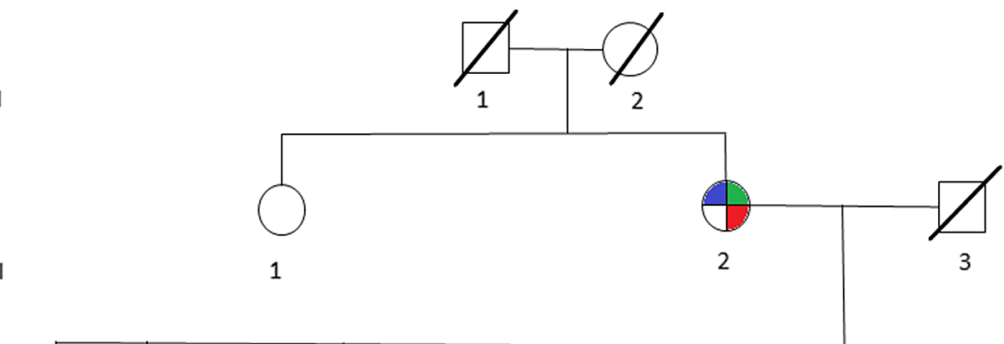

II

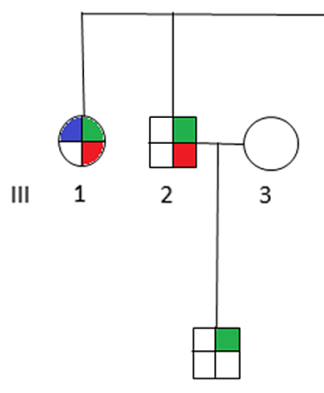

IV

1

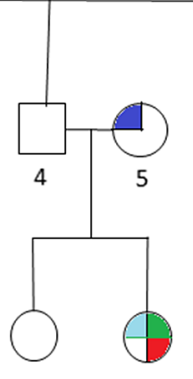

2

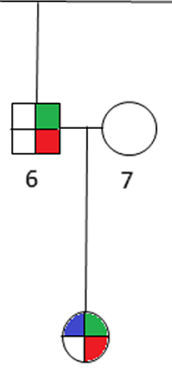

4

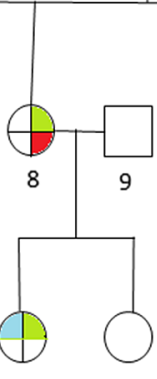

5

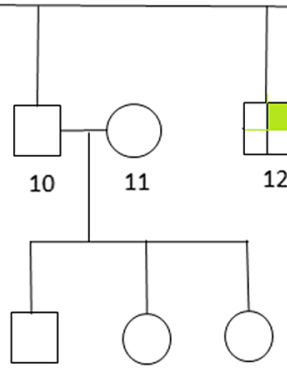

8

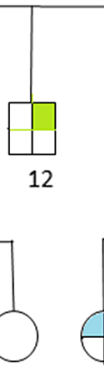

910

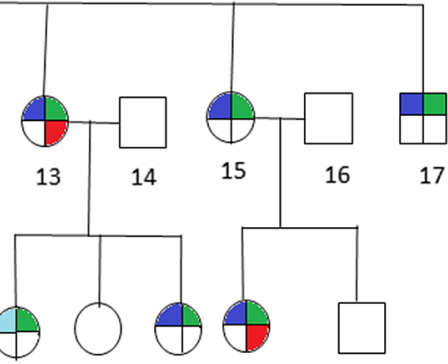

14

Figure 1: (Color online) Pedigree of multigenerational family with multiple members affected with migraine (blue), vertigo (red), motion sickness (green), or probably affected with migraine (light blue), or probably affected with motion sickness (light green). Affected members present with individual phenotype or combination of any two or all three phenotypes, indicated by the corresponding colors.

The maximum two-point LOD and maximum multipoint LOD scores for each genetic model employed and each of the three phenotypes examined are displayed in Tables 3 and 4. Prior to an adjustment for multiple testing, several scores appear suggestive of linkage as defined by Lander and Kruglyak. ${ }^{13}$ However, after adjusting the corresponding $p$-values, these scores only achieved borderline suggestive significance.

\section{DiscuSSION}

Family-based studies have identified many migraine susceptibility loci. ${ }^{1}$ In addition, as of 2017 , five major migraine genomewide association studies (GWAS) have been performed through collaborations and consortia. These have implicated 38 different susceptibility loci for migraine with or without aura. ${ }^{1,14}$

In our study, linkage analysis was performed for three phenotypes, motion sickness, vertigo, and migraine without aura.
Our analysis provides evidence suggesting a distinct pattern of linkage for each of these phenotypes to different chromosomes. Although none of the two-point or multipoint LOD scores reached statistical significance, prior to adjusting for multiple testing there are a number of suggestive LOD scores implicating different susceptibility genes depending upon the phenotype analyzed (Tables 3 and 4).

Our two-point and multipoint analyses, employing both high and low dominant models of incomplete penetrance for the migraine phenotype, suggest linkage with a maximum two-point score of 2.51 at marker GATA21F05 (9q13-q22) on chromosome 9 (Tables 3 and 4). Susceptibility loci for migraine on chromosome 9 have been previously reported. For example, the occipitotemporal lobe epilepsy/migraine with aura trait was linked to chromosome $9 q^{15}$ and a visual migraine aura trait to $9 \mathrm{q} 21-\mathrm{q} 22 .{ }^{16}$ In addition, chromosome 9q22.22 locus was identified in genome-wide linkage analysis of migraine in population of Norfolk 
Island, Australia. ${ }^{17}$ Furthermore, a single nucleotide polymorphism on chromosome 9q33.1 locus was identified by metaanalysis of data from genome-wide association studies of migraine performed in various populations. ${ }^{14,18}$ However, although these loci do map to chromosomes 9, none of them localize to the specific chromosome locus identified by our investigation. Utilizing the recessive model with this trait results in LOD scores that are less robust than those obtained for the dominant model with the maximum two-point score at marker ATA2A03 on chromosome 4 (4q21.23). Previously, loci at chromosome $4 q 24$ and $4 q 12$ were reported associated with migraine in a GWAS meta-analysis. ${ }^{14}$ Once again, these do not map to the specific chromosome 4 locus identified in our study.

The lifetime prevalence for migraine is about $16 \%$, vertigo is $7 \%$, and the comorbidity of these both occurring is $3.2 \%$. There has been research investigating not only the relationship of vertigo to migraine but also the genetics of vertiginous syndrome. ${ }^{19-21}$ Vestibular migraine manifests as vertigo presenting clinically with attacks of spontaneous vertigo lasting seconds to days. These attacks may be accompanied with headache, phonophobia, photophobia, central spontaneous or positional nystagmus, and less commonly, unilateral vestibular hypofunction. $^{22,23}$ In a study of a large family with multiple members suffering migraine and migraine-associated vertigo, identity by descent analysis was performed. Depending upon variation in penetrance and phenocopy levels, putative LOD scores analyzing only the migraine-associated vertigo affected females ranged from 1.34 to 1.9 for linkage to a $6.7-\mathrm{Mb}$ interval on chromosome 11q (67957871-74605123 NCBI Build 34). ${ }^{24}$

In our analysis of only vertigo, there are different LOD scores depending upon the inheritance model selected (Tables 3 and 4). The highest two-point LOD score was obtained by employing a recessive model with high penetrance to genetic marker ATA82B02N on chromosome 18 (18q22.3). The highest twopoint LOD score with the dominant model for vertigo maps to chromosome 11 at marker ATA33B03Z (OR51A6P, 11p15.4). This localizes close to a previously reported genetic marker, MRVI1 (rs4910165) for migraine at $11 \mathrm{p} 15.4$. We will be analyzing this locus further in future studies.

Depending upon the model employed, our analysis of motion sickness alone produced maximum two-point LOD scores for markers GATA124F08 on chromosome 1 (1q32.2) and 165zf8ZP on chromosome 4 (4q35) (Tables 3 and 4). Motion sickness is associated with both migraine headaches, vertigo, and postoperative nausea and vomiting (PONV). ${ }^{25-27}$ It has been observed that vertigo occurs in patients who habitually suffer from motion sickness, and who have a history of migraine, either with or without aura. Furthermore, although the mechanism of this susceptibility is not well understood, motion sickness occurs in approximately $50 \%$ of migraine sufferers. It is postulated that it is due to vestibular dysfunction secondary to vasomotor disturbances during migraine attacks, hyper-excitability of brainstem circuits that produce symptoms of motion sickness and migraine, and heightened susceptibility to visual illusions of movement. ${ }^{28,29}$ There have been few reports investigating the genetics of motion sickness. In one recent study, individuals contributing samples to the 23 and Me database were analyzed for associations of motion sickness, PONV, and migraines. Although the clinical data were self-reported, which is an inherent weakness of such a study, the sample size is large consisting of 80,494 people. Interestingly, 35 SNPs were found associated at the genomewide level with motion sickness. ${ }^{25}$ None of these loci localize to the chromosome 4 or chromosome 1 markers detected in our study of the motion sickness phenotype. Although in the GWAS on motion sickness there are SNPs localizing to 4p15.1, 4q34.3, $9 \mathrm{p} 21.1$, and $9 \mathrm{p} 21.2$, only the $9 \mathrm{q} 21.31$ locus overlaps with the 9q13-q22 locus detected in our study for the migraine phenotype. A number of the SNPs reported in that GWAS study including rs10970305 (ACO1 gene), rs2150864 (LINGO2 gene), rs149951341 (TLE4 gene), and rs1782031 (TUSC1 gene) all fall within the migraine locus detected in our study at GATA21F05 (9q13-q22). ${ }^{25}$ In addition, GWAS identified SNP rs10514168 (18q22.3) near TSHZ1 gene to be associated with motion sickness. $^{25}$ This is in the same chromosome region $18 \mathrm{q} 22.3$ as the locus identified in our analysis of the vertigo phenotype only.

These are interesting results that suggest an overlap between susceptibility genes for migraine, vertigo, and motion sickness. We are in the process of analyzing these chromosomes further to confirm and extend these results.

In this family, there is evidence suggesting that there are separate genes conferring susceptibility to migraine and the associated comorbid conditions vertigo and motion sickness. Although modeled as autosomal recessive or dominant in our analysis, in this family neither migraine, vertigo, or motion sickness are transmitted in a simple Mendelian fashion but involve many different genes. The results of the GWAS studies indicate that there are a number of susceptibility genes involved in the development of a migraine. Recently, the results of these studies have been extended by an analysis of families with migraine where certain common genetic variants are overrepresented contributing to a familial aggregation of this disorder. ${ }^{30} \mathrm{It}$ is likely that there are both inter- and intra-familial issues of gene penetrance and expressivity further affected by many triggers that include hormonal changes, sleep deprivation, or stress. These factors result in a cumulative threshold effect to the ultimate development of a specific migraine attack.

\section{Conclusions}

Our study highlights the challenges of investigating complex disorders such as migraine and the value of studying large well characterized families. The identification of gene(s) involved in migraine headaches and the associated neurotologic symptoms are important. Such discoveries may facilitate improved diagnosis and the development of effective and personalized treatments of patients suffering from these disorders.

\section{ACKNOWLEDGEMENTS}

We are grateful to the family members for their participation in this study.

\section{Disclosures}

All authors report no conflict of interest.

\section{Statement of Authorship}

All authors contributed to initial drafts of this publication, RPG and LRP revised later drafts. All authors reviewed and 
approved the final draft. The neurological examinations were performed by RPG, PDK, and PAH, and the statistical analysis was performed by MAL. PLR was involved in generation of genetic data. RPG was involved in supervision of all aspects of the study.

\section{REFERENCES}

1. Sutherland HG, Griffiths LR. Genetics of migraine: insights into the molecular basis of migraine disorders. Headache 2017;57(4):537-69.

2. GBD 2015 Neurological Disorders Collaborator Group. Global, regional, and national burden of neurological disorders during 1990-2015: a systematic analysis for the Global Burden of Disease Study 2015. Lancet Neurol. 2017;16(11):877-97.

3. Russell MB, Iselius L, Olesen J. Migraine without aura and migraine with aura are inherited disorders. Cephalalgia 1996;16(5):305-9.

4. Russell MB, Ulrich V, Gervil M, Olesen J. Migraine without aura and migraine with aura are distinct disorders. A population-based twin survey. Headache 2002;42(5):332-36.

5. Honkasalo ML, Kaprio J, Winter T, Heikkilä K, Sillanpää M, Koskenvuo M. Migraine and concomitant symptoms among 8167 adult twin pairs. Headache 1995;35(2):70-8.

6. Mulder EJ, Van Baal C,Gaist D, et al. Genetic and environmental influences on migraine: a twin study across six countries. Twin Res. 2003;6(5):422-31.

7. Polderman TJ, Benyamin B, de Leeuw CA, et al. Meta-analysis of the heritability of human traits based on fifty years of twin studies. Nat Genet. 2015;47(7):702-9.

8. Classification and diagnostic criteria for headache disorders, cranial neuralgias and facial pain. Headache Classification Committee of the International Headache Society. Cephalalgia 1988;8 Suppl 7:1-96.

9. O'Connell JR, Weeks DE. PedCheck: a program for identifying genotype incompatibilities in linkage analysis. Am J Hum Genet. 1998;63:259-66.

10. Terwillger J, Ott J. Handbook of genetic linkage. Baltimore, MD: Johns Hopkins University Press; 1994.

11. Sobel E,Lange K. Descent graphs in pedigree analysis: applications to haplotyping, location scores, and marker sharing statistics. Am J Hum Genet. 1996;58:1323-37.

12. Benjamini Y,Hochberg Y. Controlling the false discovery rate: a practical and powerful approach to multiple testing. J Royal Stat Soc Ser B. 1995;57(1):289-300.

13. Lander E,Kruglyak L. Genetic dissection of complex traits: guidelines for interpreting and reporting linkage results. Nat Genet. 1995;11:241-47.
14. Gormley P, Anttila V, Winsvold BS, et al. Meta-analysis of 375, 000 individuals identifies 38 susceptibility loci for migraine. Nat Genet. 2016;48(8):856-66. Erratum in: Nat Genet. 2016; 48(10): 1296.

15. Deprez L, Peeters K, Van Paesschen W, et al. Familial occipitotemporal lobe epilepsy and migraine with visual aura: linkage to chromosome 9q. Neurology 2007;68(23):1995-2002.

16. Tikka-Kleemola P, Artto V, Vepsäläinen S, et al. A visual migraine aura locus maps to 9q21-q22. Neurology 2010;74(15): 1171-7.

17. Cox HC, Lea RA, Bellis C, et al. Heritability and genome-wide linkage analysis of migraine in the genetic isolate of Norfolk Island. Gene 2012;494(1):119-23.

18. Anttila V, Winsvold BS, Gormley P, et al. North American Brain Expression Consortium; UK Brain Expression Consortium; International Headache Genetics Consortium. Genome-wide metaanalysis identifies new susceptibility loci for migraine. Nat Genet. 2013;45(8):912-17.

19. Cha YH, Baloh RW. Migraine associated vertigo. J Clin Neurol. 2007;3(3):121-6.

20. Gizzi MS, Peddareddygari LR, Grewal RP. A familial form of benign paroxysmal positional vertigo maps to chromosome 15 . Int J Neurosci. 2015;125(8):593-6.

21. Frejo L, Giegling I, Teggi R, Lopez-Escamez JA, Rujescu D. Genetics of vestibular disorders: pathophysiological insights. J Neurol. 2016;263 Suppl 1:S45-S53.

22. Versino M, Sances G, Anghileri E, et al. Dizziness and migraine: a causal relationship?. Funct Neurol. 2003;18(2):97-101.

23. Lempert T, Neuhauser H. Epidemiology of vertigo, migraine and vestibular migraine. J Neurol. 2009;256(3):333-8.

24. Lee H, Jen JC, Cha YH, Nelson SF, Baloh RW. Phenotypic and genetic analysis of a large family with migraine-associated vertigo. Headache 2008;48(10):1460-7.

25. Hromatka BS, Tung JY, Kiefer AK, Do CB, Hinds DA, Eriksson N. Genetic variants associated with motion sickness point to roles for inner ear development, neurological processes and glucose homeostasis. Hum Mol Genet. 2015;24(9):2700-8.

26. Zhang LL, Wang JQ, Qi RR, Pan LL, Li M, Cai YL. Motion sickness: current knowledge and recent advance. CNS Neurosci Ther. 2016;22(1):15-24.

27. Golding JF. Motion sickness susceptibility. Auton Neurosci. 2006;129(1-2):67-76.

28. Drummond PD. Triggers of motion sickness in migraine sufferers. Headache 2005;45(6):653-6.

29. Marcus DA, Furman JM, Balaban CD. Motion sickness in migraine sufferers. Expert Opin Pharmacother. 2005;6(15):2691-7.

30. Gormley P, Kurki MI, Hiekkala ME, et al. Common variant burden contributes to the familial aggregation of migraine in 1, 589 families. Neuron 2018;98(4):743-53.e4. 